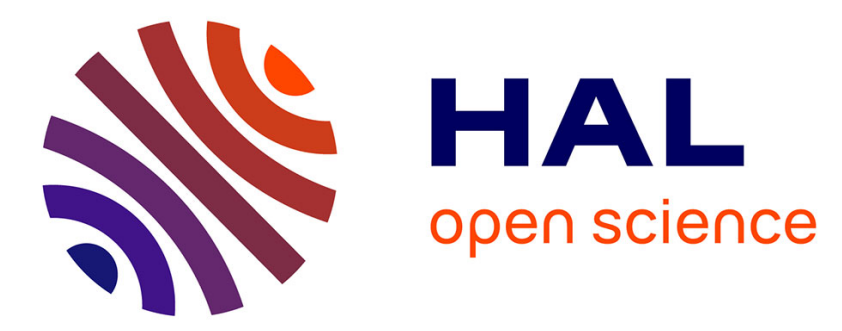

\title{
IONIZING COLLISIONS OF LASER-EXCITED RARE GAS ATOMS
}

\author{
W. Bussert, T. Bregel, J. Ganz, K. Harth, A. Siegel, M.-W. Ruf, H. Hotop, H. \\ Morgner
}

\section{- To cite this version:}

W. Bussert, T. Bregel, J. Ganz, K. Harth, A. Siegel, et al.. IONIZING COLLISIONS OF LASEREXCITED RARE GAS ATOMS. Journal de Physique Colloques, 1985, 46 (C1), pp.C1-199-C1-214. 10.1051/jphyscol:1985120 . jpa-00224492

\section{HAL Id: jpa-00224492 https://hal.science/jpa-00224492}

Submitted on 1 Jan 1985

HAL is a multi-disciplinary open access archive for the deposit and dissemination of scientific research documents, whether they are published or not. The documents may come from teaching and research institutions in France or abroad, or from public or private research centers.
L'archive ouverte pluridisciplinaire HAL, est destinée au dépôt et à la diffusion de documents scientifiques de niveau recherche, publiés ou non, émanant des établissements d'enseignement et de recherche français ou étrangers, des laboratoires publics ou privés. 

and $H$. Morgner ${ }^{+}$

Fachbereich Physik, Universität Kaiserslautem, 6750 Kaiserszauterm, F.R.G.

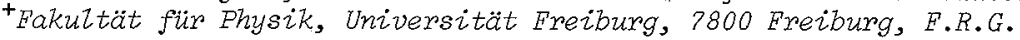

Résumé : Nous avons utilisé la spectrométrie de masse et la spectrométrie d'électrons pour étudier l'ionisation. d'atomes d'argon et de krypton dans des collisions, aux énergies thermiques, avec des atomes de Ne à courte durée de vie $\left(2 \mathrm{p}^{5} 3 \mathrm{p}, \mathrm{J}=1,2,3\right)$ excités par laser. Les sections efficaces dépendent fortement de 1'état excité ; leur comportement est bien reproduit par des calculs fondés sur les courbes théoriques d'énergie potentie1le et sur I'existence d'un seul état autoionisant à décroissance exponentielle. Les rendements total et partiel d'ions et les spectres d'électrons présentent des effets de polarisation importants; on ne peut les expliquer que par des probabilités d'autoionisation dépendant de $\Omega$ et favorisant le transfert $d^{\prime}$ 'électrons $\sigma \longrightarrow \sigma$.

Abstract: Using mass spectrometry and electron spectrometry, we have studied ionization of $\mathrm{Ar}$ and $\mathrm{Kr}$ atoms in thermal energy collisions with laser-excited short-lived $\mathrm{Ne}\left(2 \mathrm{p}^{5} 3 \mathrm{p} \mathrm{J}=1,2,3\right)$ atoms. The cross sections show a strong statedependence, which is reproduced in calculations based on theoretical potential energy curves and a single exponential autoionization width. Significant polarization effects have been observed in the total and partial ion yields and in the electron spectra; they can only be explained with $\Omega$-dependent autoionization probabilities favouring $\sigma \rightarrow \sigma$ electron transfer.

\section{Introduction}

The availability of tunable lasers, especially of stabilized cw single mode dye lasers, has made possible detailed studies of electronic and atomic collisions/e.g. 1-18\%. In the last years, we have started a program to investigate ionizing collisions of state-selected heavy rare gas metastable atoms $X\left(\mathrm{mp}_{5}^{5}(\mathrm{~m}+1) \mathrm{s}^{3} \mathrm{P}_{2}{ }_{0}\right)$ ( $\mathrm{X}=\mathrm{Ne}, \mathrm{Ar}$, $\mathrm{Kr}, \mathrm{Xe}) / 11,12 /$ and of laser-excited, short-lived states $\mathrm{X}\left(\mathrm{mp}^{5} \mathrm{nl}\right) / 13-18 / \mathrm{by} \mathrm{high}$ resolution electron spectrometry and mass spectrometry. It is our goal to obtain insight into the ionization mechanism in collisions with states of medium to very high excitation (Rydberg states næ10) and to test potential energy curves for such multistate systems. For this purpose, we compare the results obtained for many multiplet states, which are excited or state-selected by laser optical pumping of intense collimated metastable rare gas beams. We study the dependence of the cross sections on collision energy and on the polarization of the pumping laser with respect to the axis of the (average) relative velocity of the collision system. For the excited heavy rare gas atoms $X\left(\mathrm{mp}^{5} \mathrm{nl}\right)$ it is of interest that polarization will be transferred to both the valence electron and to the core. Especially the polarization of the orbital angular momentum of the core may play a decisive role for the autoionization of the collision system. In this paper, we report in detail the results obtained for $\mathrm{Ne}\left(2 \mathrm{p}^{5} \mathrm{zp} \mathrm{J}=1,2,3\right)+\mathrm{Ar}$ together with calculated potential energy curves; in addition, we present first results for $\mathrm{Ne}\left(2 \mathrm{p}^{5} 3 \mathrm{p} \mathrm{J=1,2}\right)+\mathrm{Kr}$.

\section{Experimental}

Fig. 1 shows a schematic arawing of the apparatus. A thermal energy, mixed metastable $\mathrm{Ne}\left(2 \mathrm{p}^{5} 3 \mathrm{~s}^{3} \mathrm{P}_{2,0}\right)$ beam, originating from a separately-pumped cold cathode discharge source $/ 11 /$, is highly collimated $(\leq 1: 100)$ at the entrance to the reaction region, 
where it is transversely excited by a stabilized single mode dye laser, tuned to the ${ }^{20} \mathrm{Ne}(3 \mathrm{~s} \rightarrow 3 \mathrm{p})$ transition of interest (Fig. 2). The velocity distribution of the

$\mathrm{Ne}\left(3 \mathrm{~s}{ }^{3} \mathrm{P}_{2}, 0\right)$ atoms has been studied by time-of-flight techniques; under normal operation of the source (current $10 \mathrm{~mA}$, source pressure 10-30 mbar, wall temperature around $300 \mathrm{~K})$ the average metastable velocity $\overline{\mathrm{V}}$ was found to be $800 \mathrm{~m} / \mathrm{s}$ with a FWH of about $30 \%$ of $\bar{v}$. Typical $\mathrm{Ne}^{*}$ intensities from our source are $(1-2) \cdot 10^{14} / \mathrm{s} \cdot \mathrm{sr}$. Admixture of He gas results in a shift of the Ne* velocity distribution towards higher $\nabla$, accompanied by a small increase in $\mathrm{Ne}^{*}$ intensity. With the addition of He at an amount comparable with the normal Ne pressure, we obtain a Ne beam with $\bar{v}=1200 \mathrm{~m} / \mathrm{s}$ (FWHM 30\%) and a He* fraction below 3\%. The latter does not produce problems in the interpretation of electron spectrometric data.

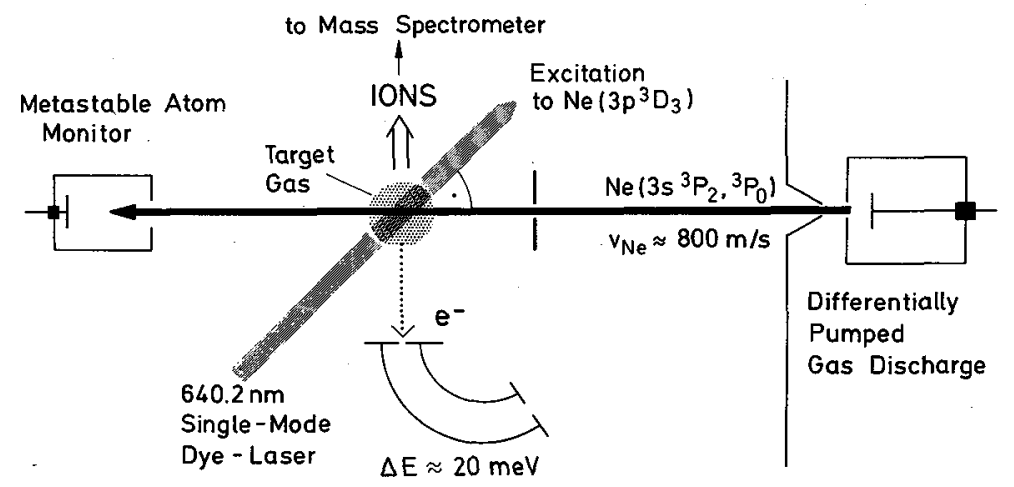

Fig. 1: Schematic Drawing of Experimental Setup

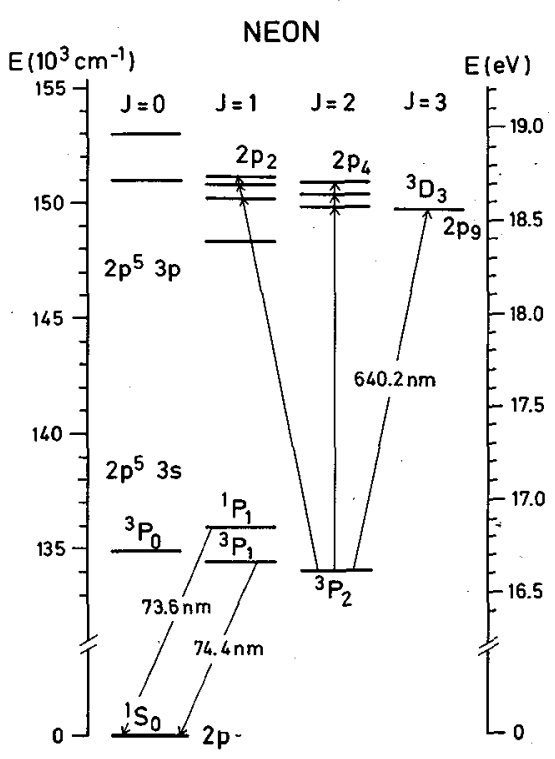

Fig. 2 : Neon Ēnergy Levels
In this paper we present data obtained with two different setups:

i) In the first (Fig. 1), we use a static target gas (density $(2-6) \cdot 10^{12} / \mathrm{cm}^{3}$ ) for electron spectrometry, $\leqslant 10^{11} / \mathrm{cm}^{3}$ for ion measurements). Here, the $\mathrm{Ne}^{*}$ velocity is the relevant quantization axis for studies of the polarization dependence. A $127^{\circ} \mathrm{cylin}-$ drical condenser /11-15/ or a two-stage hemispherical condenser /16,18/ have been usa for electron spectrometry. A quadrupole mass spectrometer /15,17/ or a time-offlight mass spectrometer sample the ions. The target chamber temperature was (295300) $\mathrm{K}$; for the system $\mathrm{Ne}^{*}+\mathrm{Ar}$ with $\overline{\mathrm{v}}_{\mathrm{Ne}}=800 \mathrm{~m} / \mathrm{s}$, an average collision energy $\mathrm{E}_{\mathrm{rel}}=58 \mathrm{meV}$ results.

ii) In the second setup, an effusive target beam (target density around $5 \cdot 10^{12} / \mathrm{cm}^{3}$ eros ses the $\mathrm{Ne}^{*}$ beam at right angle. Here, the quantization axis is given by the vector of the average relative velocity between the $\mathrm{Ne}^{*}$ and the target beam, tilted away from $\overrightarrow{\mathrm{V}}_{\mathrm{Ne}}$. This apparatus has been used before for photoelectron spectrometry and incorporates two separate, rotatable two-stage hemispherical condensers, allowing the mea- 
surement of electron angular distributions $/ 19 /$.

In both setups $i$ ) and $i$ ) an electron energy resolution of (20-30) meV was employed by appropriate choice of the constant pass energy. The energy dependence of the overall transmission of the electron spectrometers was determined by VUV photoelectron spectrometry of $\mathrm{O}_{2}$, CO and $\mathrm{N}_{2} /$ e.g. 12/. The electron spectra shown below have been transmission-corrected. All spectra were measured by multichannel scaling techniques as described before $/ 11,12 /$.

Next, we discuss the important aspects of the laser excitation of the metastable $\mathrm{Ne}^{*}$ beam. Using a metastable state selection method involving multimode dye lasers $/ 11$, $20 \%$, we have repeatedly determined the ${ }^{3} \mathrm{P}_{2} /{ }^{3} \mathrm{P}_{0}$-composition of the normal $\mathbb{N e}{ }^{*}$ beam (without He seed gas) as $5.1: 1$ and the ${ }^{3} \mathrm{P}_{2} /{ }^{3} \mathrm{P}_{0}$-ionization cross section ratio for $\mathrm{Ar}$ at $\bar{v}_{N e}=800 \mathrm{~m} / \mathrm{s}$ as $0.81 \pm 10 \% / 11 /$. Therefore, the ${ }^{3} \mathrm{P}_{2} /{ }^{3} \mathrm{P}_{0}$-ratio of the product "density* ionization cross section" is given by $\mathrm{n}_{2} \sigma_{2} / \mathrm{n}_{0} \sigma_{0}(\mathrm{Ar})=4_{4} .1$. Similar ratios are calculated for the target atoms $\mathrm{Kr}$, $\mathrm{Xe}, \mathrm{Hg} / 11 \%$.

In the measurements, we have always excited the ${ }^{20} \mathrm{Ne}\left(3 \mathrm{~s}{ }^{3} \mathrm{P}_{2}\right)$-fraction $(76 \%)$ of the $\mathrm{Ne}^{*}$ beam. We first discuss the transition ${ }^{20} \mathrm{Ne}\left(3 \mathrm{~s} \quad{ }^{3} \mathrm{P}_{2} \rightarrow 3 \mathrm{p} \quad{ }^{3} \mathrm{D}_{3} \triangleq 2 \mathrm{p}_{9}\right.$ Paschen notation) at $640.2 \mathrm{~nm}$; it is unique because spontaneous electric dipole decay from the upper level leads always back to the pumped state. Therefore, a substantial quasi-stationary upper state population can be achieved together with a well-defined polarization of both the upper and lower state. In pumping this transition, we have used a nearly parallel beam (diameter about $4 \mathrm{~mm}$ ) of 100-200 $\mathrm{mW}$ power from a stabilized single mode dye ring laser (Coherent 699-21, dye DCM). Under these conditions, the pumped ${ }^{20} \mathrm{Ne}\left(3 \mathrm{~s}{ }^{3} \mathrm{P}_{2}\right)$ atoms spend about $5 \mu \mathrm{s}$ in the laser beam and undergo 250 spontaneous emissions. With linear laser polarization only even state multipole moments are present with a rank up to 2.J. As we could show by photoelectron angular distribution studies of $\mathrm{Ne}\left(3 \mathrm{p}{ }^{3} \mathrm{D}_{3}\right)$, ionized by $351.1 \mathrm{~nm}$ radiation $/ 16 /$, the theoretically expected alignment is actually achieved under our excitation conditions. We note, that the saturation broadened linewidth is typically 100-150 MHz (FWHM); therefore, the influence of the Doppler effect (FWHM $\approx 20 \mathrm{MHz}$ for a collimation ratio of $1: 100$ ) is negligible in the absence of beam scattering, i.e. for very thin target conditions, as met in the ion measurements. Here, almost $50 \%$ of the pumped ${ }^{20} \mathrm{Ne}\left(3 \mathrm{~s}{ }^{3} \mathrm{P}_{2}\right)$ atoms are present in the $2 p_{g}$-state (excitation fraction $\left.f=(45 \pm 5) \%\right)$. For electron spectrometry, the target density has to be increased to such a level that elastic.scattering of the $\mathrm{Ne}^{*}$ beam between the collimating aperture and the reaction region leads to a non-negligible broadening of the effective Doppler profile and a reduction of the $2 p_{\text {g-frac- }}$ tion. Even here, values of $\mathrm{f} \approx 25 \%$ are easily obtained, however, resulting in $\mathbb{N e}(2 \mathrm{pg})-$ induced electron counting rates which are comparable with those due to $\mathrm{Ne}\left(3 \mathrm{~s}{ }^{3} \mathrm{P}_{2}\right)$.

In Fig. 3, we have sketched the different choices of laser poiarization applied in

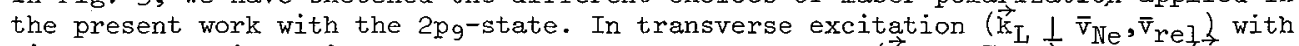

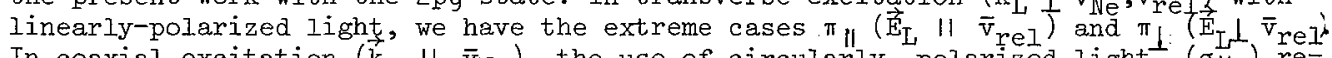
In coaxial excitation $\left(\vec{k}_{T} \| \bar{v}_{N e}\right)$, the use of circularly polarized light (oll) resulțs in a pure asymptotic state; coaxial excitation is velocity-selective to a degree determined by the saturation-broadened excitation width (under our conditions $\Delta \mathrm{v} / \overline{\mathrm{v}} \approx 10 \%)$. The numbers given in Fig. 3 for the relative asymptotic $\Omega=\left|\mathrm{m}_{J}\right|$ and $\mathrm{m}_{\ell}-\mathrm{po}$ pulations correspond to the diagonal elements of the respective density matrix and illustrate the polarization-induced variations in the boundary conditions for the collision system. As a result of the non-perfect kinematics of our experiment, especially for the beam-gas configuration $i)$, some averaging occurs and will result in a reduction of the polarization effect /21\%. More importantly, we emphasize that our measured quantities represent averages over all contributing impact parameters (typically $\left.0-8 a_{0}\right)$.

We now discuss the procedure to study ionizing collisions with $\mathbb{N e}(3 p \mathrm{~J}=1,2)$ states. As is clear from Fig. 2, laser excitation to the Ne(3p J=1,2) levels suffers from their spontaneous decay to non-pumped $\mathrm{Ne}(3 \mathrm{~s})$-states. Therefore, the "effective residence time" $\tau_{\text {eff }}$ in these truly short-lived Ne(3p) states is comparable with their natural lifetime $\tau(\approx 20 \mathrm{~ns} / 22 /)$. Compared with the $\mathrm{Ne}\left(3 \mathrm{p}{ }^{3} \mathrm{D}_{3}\right)$-state, we expect a loss in signal (assuming comparable cross sections) of two orders of magnitude. By 
careful reduction of background (e.g. due to scattered metastables and VUV fluorescence $\left.\mathrm{Ne}(3 \mathrm{~s} \mathrm{~J}=1) \rightarrow \mathrm{Ne}\left(2 \mathrm{p}^{6}{ }^{1} \mathrm{~S}_{0}\right)\right)$, using two-stage condensers, we have succeeded in measuring electron spectra due to the short-lived $N e(3 p \mathrm{~g}=1,2)$-states with adequate signal-to-background ratio.

In this work we have used the following excitation conditions: a cylindrical lens ( $f=50 \mathrm{~cm}$ ) produces a line waist of the laser with a width of about $0.2 \mathrm{~mm}$, located in the center of the reaction region (width seen by the electron detector about $2 \mathrm{~mm}$ ). Thereby, excitation outside the detection volume is ruled out, and the atoms spend about $250 \mathrm{~ns}(12 \tau)$ in the laser beam, allowing for complete removal of the pumped magnetic sub-states by subsequent absorption-spontaneous emission cycles. Under these circumstances, the background-corrected, energy-integrated electron intensities are proportional to the respective ionization cross section and to the effective residence time $\tau$ eff in the upper state $k$. $\tau_{\text {eff may be expressed as the product }}$ of the natural lifetime $\tau_{k}$ times an efficiency factor $n$, which accounts for the details of the transition, $i . e$. which percentage of the magnetic substates $m_{i}$ in the lower state $i$ can be pumped for a given laser polarization and which fraction of the spontaneous decays from the upper state $k$ leads back to the pumped state $i$. The natural lifetimes $\tau_{k}$ are precisely known /22/, and we have calculated the efficiency factor $n$ for all the $3 s \rightarrow 3 p$ transitions and polarizations of interest, using the rate equation approach. Magnetic fields are assumed to be absent, i.e. below $10^{-6} \mathrm{~T}$ for practical purposes; in our apparatus, a double mumetal-shielding reduces the magnetic field to values around $10^{-7} \mathrm{~T} / 19 /$. Measurements with linearly-polarized excitation have been carried out, yielding significant changes between $m_{l}$ and $\pi_{1}$ for $\mathrm{Ne}(3 \mathrm{p} J=2)+\mathrm{Ar}$, as will be discussed elsewhere. Here we deal only with excitation by unpolarized light, which was realized by using a Hanle-type polarization scrambler (Fa. Halle, Berlin). In this case, the efficiency factor $n$ is simply given by: $n_{\mathrm{Ki}}=1 /\left(1-\mathrm{A}_{\mathrm{ki}} / \mathrm{A}_{\mathrm{K}}\right)$, where $\mathrm{A}_{\mathrm{ki}}$ is the spontaneous transition rate from the upper state $\mathrm{k}$ to the pumped state $i$-here: $\operatorname{Ne}\left(3 \mathrm{~s}{ }^{3} \mathrm{P}_{2}\right)$ - and $A_{k}=1 / \tau_{k}$ is the total spontaneous transition rate from the upper state $k$, as listed in $/ 22 /$.

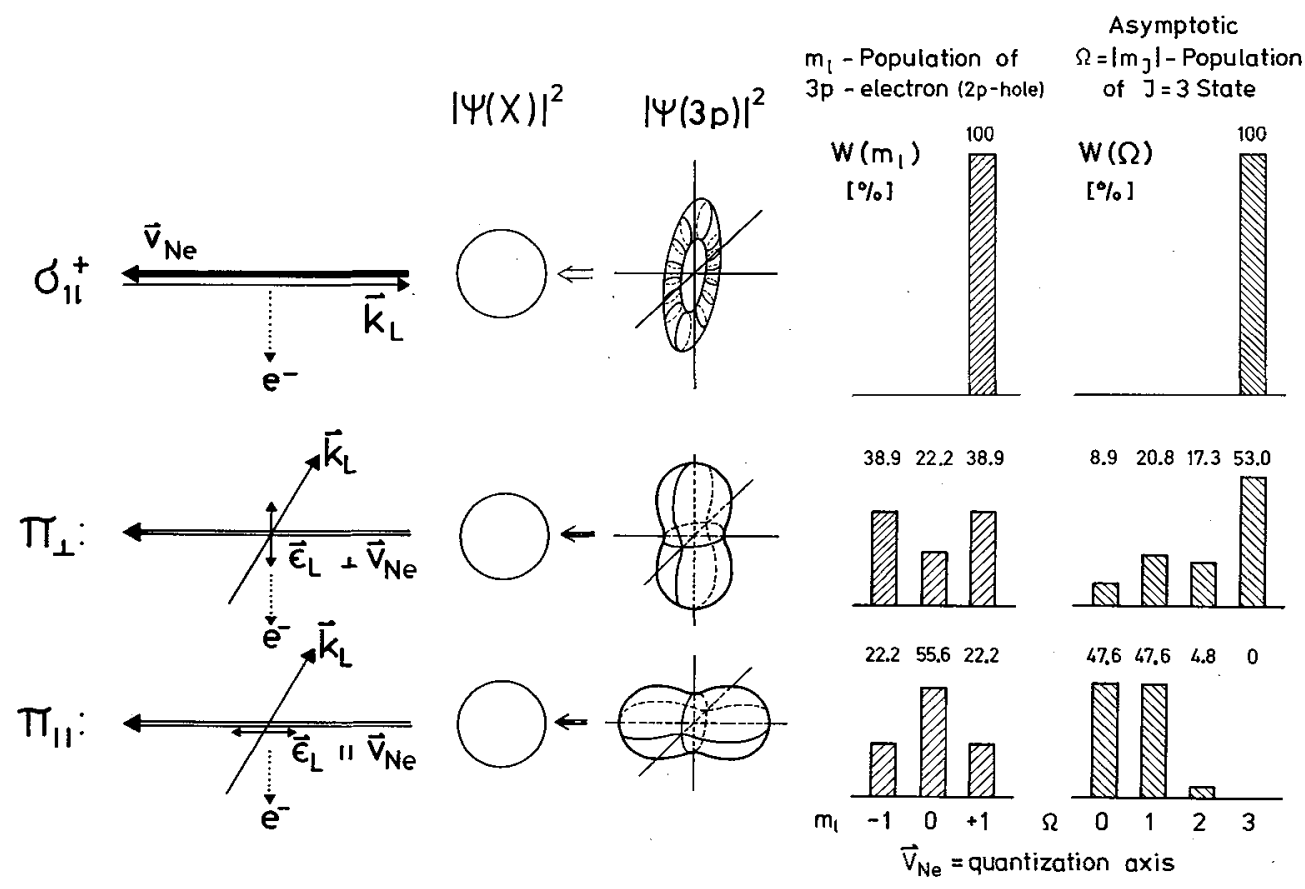

Fig. 3: The three different polarizations and their corresponding asymptotic $m_{I}-$ and $\Omega=\left|m_{J}\right|$-populations 
3. Experimental Results

\section{1 Polarization Dependence of the Ion Production in $\mathrm{Ne}\left(3 \mathrm{p}{ }^{3} \mathrm{D}_{3}\right)$ Collisions}

With a time-of-flight mass spectrometer, which could also be used to measure the total ion yield in an effective way, we have studied the polarization dependence for ionizing collisions of $\mathrm{He}\left(3 \mathrm{p}{ }^{3} \mathrm{D}_{3}\right)\left(\overline{\mathrm{v}}_{\mathrm{Ne}}=800 \mathrm{~m} / \mathrm{s}\right)$ with several static target gases $Y$. Fig. 4 illustrates the procedure and the total ion results for $\mathrm{Y}=\mathrm{Ar}$. Without the pumping laser ("laser off"), we obtain a reference ion intensity, containing known contributions due to $\mathrm{Ne}\left(3 \mathrm{~s}{ }^{3} \mathrm{P}_{2}\right)$ (see above). With saturated $(f=(45+5) \%)$ transverse laser excitation of $20 \mathrm{Ne}\left(3 \mathrm{~s} 3 \mathrm{P}_{2}\right)$, the total ion signal increases significantly; the increase is found to depend strongly on the angle $\theta$ between the electric vector of the linearly-polarized laser and the average direction of the relative velocity $\left(=\vec{v}_{\mathrm{Ne}}\right.$ in this case). The ${ }^{3} \mathrm{P}$-fraction remains unaffected, of course. From electron spectrometry with state-selected, polarized Ne $\left(3 \mathrm{~s} \cdot{ }^{3} \mathrm{P}_{2}\right)$ we know that the polarization dependence of the $\mathrm{Ne}\left(3 \mathrm{~s}{ }^{3} \mathrm{P}_{2}\right)+\mathrm{Ar}$ cross section is very small ( $\left.\mathrm{s} 1 \%\right)$; for the evaluation of the present ion data, we neglect it. With the excitation fraction $f=0.45(5)$ the $\mathrm{Ne}\left(3 \mathrm{~s}{ }^{3} \mathrm{P}_{2}\right)$-contribution to the "laser on" data can be easily calculated from the known "laser-off" contribution, as indicated in Fig. 4. Using formulae given in /15/, one can then easily deduce the relative ionization cross sections for $\operatorname{Ne}\left(3 \mathrm{~s}{ }^{3} \mathrm{P}_{2}\right)$ and Ne $\left(3 p{ }^{3} D_{3}\right)$ and the polarization ratio $Q=\sigma\left(\pi_{11}\right) / \sigma\left(\pi_{1}\right)$ of the latter.

A Fourier analysis of the polarization angular dependence of the $\mathrm{Ne}\left(3 \mathrm{p}{ }^{3} \mathrm{D}_{3}\right)+\mathrm{Ar}$ ion yield (Fig. 4)

$$
I(\theta)=\sum_{n=0}^{3} R_{n} \cos (2 n \theta)
$$

can be used to derive the $\left|m_{J}\right|$-dependence of the cross section $/ 23 /$, as will be discussed elsewhere in detail. Here, we just note that $R_{2}, R_{3}$ were found to be negligibly small for all the studied targets; the ratio $R_{l} / R_{0}$ is then related to $Q$ simply by $Q=\left(1+R_{1} / R_{0}\right) /\left(1-R_{1} / R_{0}\right)$. For all the rare gas targets Ar, Kr, Xe a clear polarization effect was found in the total ion yield with Q $4 / 3$ (see Table 1). We have also investigated the polarization dependence of the partial cross sections, e.g. Ar+formation (Penning ionization PI) and NeAr+-formation (associative Penning ionization AI). The AI-channel always shows a much more pronounced polarization effect than the PI-channel. For the target $\mathrm{Hg}$, whose electron spectrum exhibits a very strong polarization dependence $/ 14 /$, the total ion yield was found to be practically independent of the polarization direction. Weak polarization effects (Q 21.05 ) have been observed for $\mathrm{Y}=\mathrm{N}_{2}, \mathrm{CO}$, and $\mathrm{O}_{2}$.

\begin{tabular}{|c||c||c|c|c|}
\hline TARGET & $\sigma_{\text {TOT }}^{a}\left[R^{2}\right]$ & $Q_{\text {TOTAL }}$ & $Q_{P I}$ & $Q_{A I}$ \\
\hline $\mathrm{Ar}$ & 23 & $1.33 \pm 0.07$ & $1.22 \pm 0.03$ & $2.3 \pm 0.3$ \\
$\mathrm{Kr}$ & 23 & $1.40 \pm 0.09$ & $1.29 \pm 0.04$ & $2.7 \pm 1.0$ \\
$\mathrm{Xe}$ & 29 & $1.33 \pm 0.06$ & $1.25 \pm 0.05$ & $3.0 \pm 1.8$ \\
\hline
\end{tabular}

a: Average of $\sigma\left(\pi_{11}\right)$ and $\sigma\left(\pi_{\perp}\right)$, measured relative to $\mathrm{Ne}\left(3 \mathrm{~s}{ }^{3} \mathrm{P}_{2}\right) / 11,15 /$

Table 1: Ratio $Q=\sigma\left(\pi_{1}\right) / \sigma\left(\pi_{\perp}\right)$ of the total and partial ionization cross sections for the systems $\operatorname{Ne}\left(3 \mathrm{p}^{3} \mathrm{D}_{3}\right)+\mathrm{Ar}, \mathrm{Kr}, \mathrm{Xe} .\left(\overline{\mathrm{v}}_{\mathrm{Ne}}=800 \mathrm{~m} / \mathrm{s}\right)$.

\subsection{Polarization Dependence of the Ne( $\left.3 \mathrm{p}^{3} \mathrm{D}_{3}\right)+\mathrm{Ar}$ Electron Spectrum}

We have previously reported on a polarization dependence of the electron spectra for $\mathrm{Ne}\left(3 \mathrm{p}{ }^{3} \mathrm{D}_{3}\right)+\mathrm{Ar}, \mathrm{Kr}, \mathrm{Xe} / 13 /$, using transverse $\mathrm{Ne}$ excitation $(\overline{\mathrm{V}}=800 \mathrm{~m} / \mathrm{s})$ in a beamgas setup. In the meantime, we have also measured spectra with coaxial excitation, which is facilitated by the use of the intense ring laser output. 

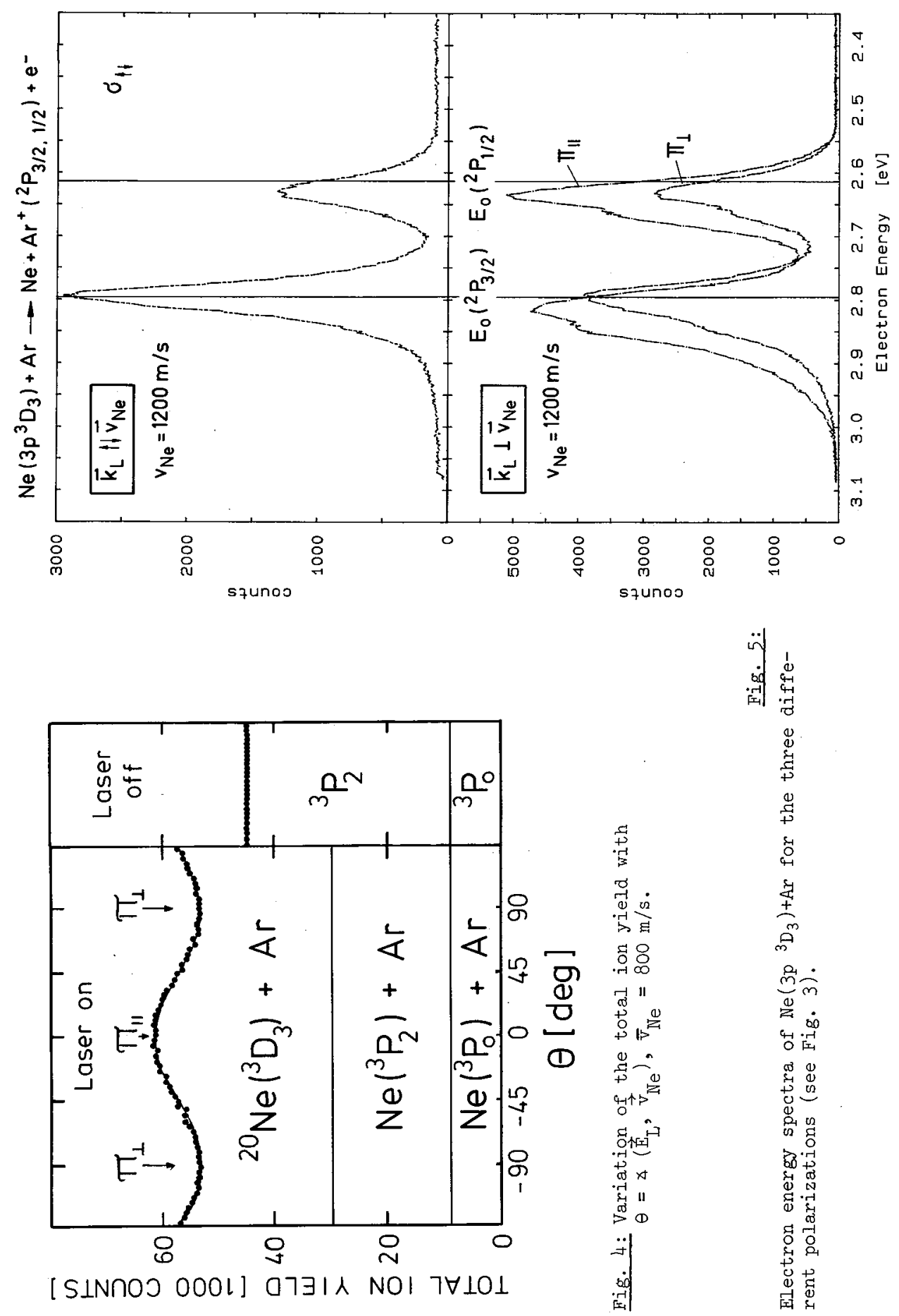
From the beam-gas electron spectra we obtain $Q=1.30$ in agreement with the ion data (Table 1). Fig. 5 shows the $\mathrm{Ne}\left(3 \mathrm{p}_{-}{ }^{3} \mathrm{D}_{3}\right)+\mathrm{Ar}$ electron spectra obtained with the beambeam apparatus for $\overline{\mathrm{V}}_{\mathrm{Ne}}=1200 \mathrm{~m} / \mathrm{s}$ ( $\overline{\mathrm{E}}_{\mathrm{rel}}=110 \mathrm{meV}$ ). The electrons are detected perpendicular to the $\mathbb{N e}^{*}$-beam in a plane which contained also the laser beam. Preliminary measurements at other electron detection angles (relative to the Ne* beam) yielded spectra, with essentially the same shape and only weak total intensity changes. The spectra in Fig. 5 show a very clear polarization dependence with a continuous trend from $\sigma_{\|}$(only $\left|\mathrm{m}_{\mathrm{J}}\right|=\Omega=3$ populated asymptotically) via $\pi 1$ (dominant $\Omega=3$ population) to $\pi l l$ (dominant $\Omega=0$ population), see Fig. 3. As has also been observed at $\overline{\mathrm{v}}=800 \mathrm{~m} / \mathrm{s}$, the $\operatorname{Ar}^{+}\left({ }^{2} \mathrm{P}_{3 / 2}\right) / \mathrm{Ar}^{+}\left({ }^{2} \mathrm{P}_{1 / 2}\right)$ branching ratio decreases, whereas the high energy part of both fine-structure peaks increases from $\sigma_{\|}$via $\pi_{1}$ to $\pi_{11}$. The latter observation is compatible with the strong polarization dependence of the Ne Artchannel, which corresponds to the high energy part of the electron peaks with $E_{e l}-E_{o}>E_{r e l}\left(E_{0}\right.$ : respective nominal energy of peaks, see e.g. $/ 11 /$ ).

From the $\pi_{\|}$- and $\pi_{\perp}$-spectra in Fig. 5, one obtains the polarization ratio $\mathrm{Q}=1.57(4)$. The increase relative to the $\overline{\mathrm{v}}_{\mathrm{Ne}}=800 \mathrm{~m} / \mathrm{s}$ data may be in part due to the better defined kinematics at $\bar{v}_{\mathrm{Ne}}=1200 \mathrm{~m} / \mathrm{s}$. For a detailed understanding of the polarization dependence of the electron spectra it is necessary to know the participating potential energy curves in order to carry out model calculations of the spectra There are four potential curves $\Omega=0^{-}, 1,2,3$ for $\mathrm{Ne}\left(3 \mathrm{p}{ }^{3} \mathrm{D}_{3}\right)+\mathrm{Ar}$ and three ionic curves for $\mathrm{NeAr}^{+}\left({ }^{2} \mathrm{~L}_{1} / 2,{ }^{2} \mathrm{II}_{3 / 2},{ }^{2} \mathrm{II}_{1 / 2}\right)$; moreover, the autoionization width, which may depend on $\Omega$, enters the problem. Here, we only give a qualitative discussion (see below) and postpone the details to a later publication.

\subsection{Electron Spectra for $\mathrm{Ne}(3 \mathrm{p} \mathrm{J}=1,2)+\mathrm{Ar}, \mathrm{Kr}$}

Using setup i) we have obtained results for $\operatorname{six} \mathrm{Ne}(3 \mathrm{p} \mathrm{J}=1,2)$ states at $\overrightarrow{\mathrm{v}}_{\mathrm{Ne}}=800 \mathrm{~m} / \mathrm{s}$, as reported last year $/ 18 /$. With the improved beam-beam apparatus ii) we have measured spectra for the same $\mathrm{six}$ states at $\bar{v}_{\mathrm{Ne}}=1200 \mathrm{~m} / \mathrm{s}$ for $\mathrm{Y}=\mathrm{A} . \mathrm{r}, \mathrm{Kr}$ and - for comparison and calibration purposes - at $\bar{v}_{N e}=800 \mathrm{~m} / \mathrm{s}$ for $\mathrm{Ne}\left(3 \mathrm{p} \mathrm{J}=2 ; 2 \mathrm{p}_{8}, 2 \mathrm{p}_{6}\right)+\mathrm{Ar}$. The results for $\overline{\mathrm{v}}_{\mathrm{Ne}}=1200 \mathrm{~m} / \mathrm{s}$ are shown in $\mathrm{Fig} .6$; unpolarized radiation was used for excitation. In Table 2, we have listed the relative cross sections deduced from the Arspectra in Fig. 6 together with the earlier results for $\bar{v}_{\mathbb{N e}}=800 \mathrm{~m} / \mathrm{s} / 18 /$. The absoIute size of the cross section scale was chosen to be compatible with that of the earlier data, which was based on a $N e\left(3 p{ }^{3} \mathrm{D}_{3}\right)+\mathrm{Ar}$ cross section of $19.7 \mathrm{~A}^{2}$ (average of $\pi_{1}$ and $\pi_{l}$ ). This value is about $15 \%$ lower than the more carefully determined average value in Table 1, but we note that the experimental uncertainty in the determination of the $\mathrm{Ne}(3 \mathrm{p} \mathrm{J}=1,2)$ cross sections relative to the $\mathrm{Ne}\left(3 \mathrm{p}{ }^{3} \mathrm{D}_{3}\right)$ cross section from their respective electron intensities so far amounts to about $+50 \%$. This uncertainty transfers to the absolute scale of the cross sections in Table 2.

As is clear from Fig. 6 and Table 2, the total cross sections show a very strong state dependence, both at $\overline{\mathrm{v}}_{\mathbb{N e}}=800 \mathrm{~m} / \mathrm{s}$ and $1200 \mathrm{~m} / \mathrm{s}$. The relative intensity for the two. ionic fine-structure channels also strongly varies from state to state; analogous differences have been found in the behaviour of the metastable $\mathrm{Ne}\left(3 \mathrm{~s}{ }^{3} \mathrm{P}_{2},{ }^{3} \mathrm{P}_{0}\right)$ states $/ 11 /$. For some states, a significant velocity dependence of the total cross sections is observed. As for the $\mathbb{N e}(3 \mathrm{p} J=1,2)+\mathrm{Kr}$. systems, Fig. 6 shows that they behave qualitatively in the same way as $\mathrm{Ne}(3 \mathrm{p} \mathrm{J}=1,2)+\mathrm{Ar}$.

In order to understand the strong state dependence of the cross sections, we have calculated potential energy curves for $\mathrm{Ne}(3 \mathrm{p})+\mathrm{Ar}$, as will be explained in the next section. Using these theoretical potentials, we have calculated total ionization cross sections of $\mathrm{Ar}$ for all the $\mathrm{Ne}(3 \mathrm{p})$ multiplet states in the thermal energy range, assuming - for simplicity - a single autoionization wiath function $\Gamma(R)$

$$
\Gamma(R)=C \exp (-\gamma R)
$$

with the eritical parameter $\gamma$ optimized such that the state dependence of the experimental cross sections (Table 2 ) is reproduced. The factor $\mathrm{C}$ plays a minor role; it is found to scale the absolute size of the calculated cross sections in an almost linear way for the discussed systems. 

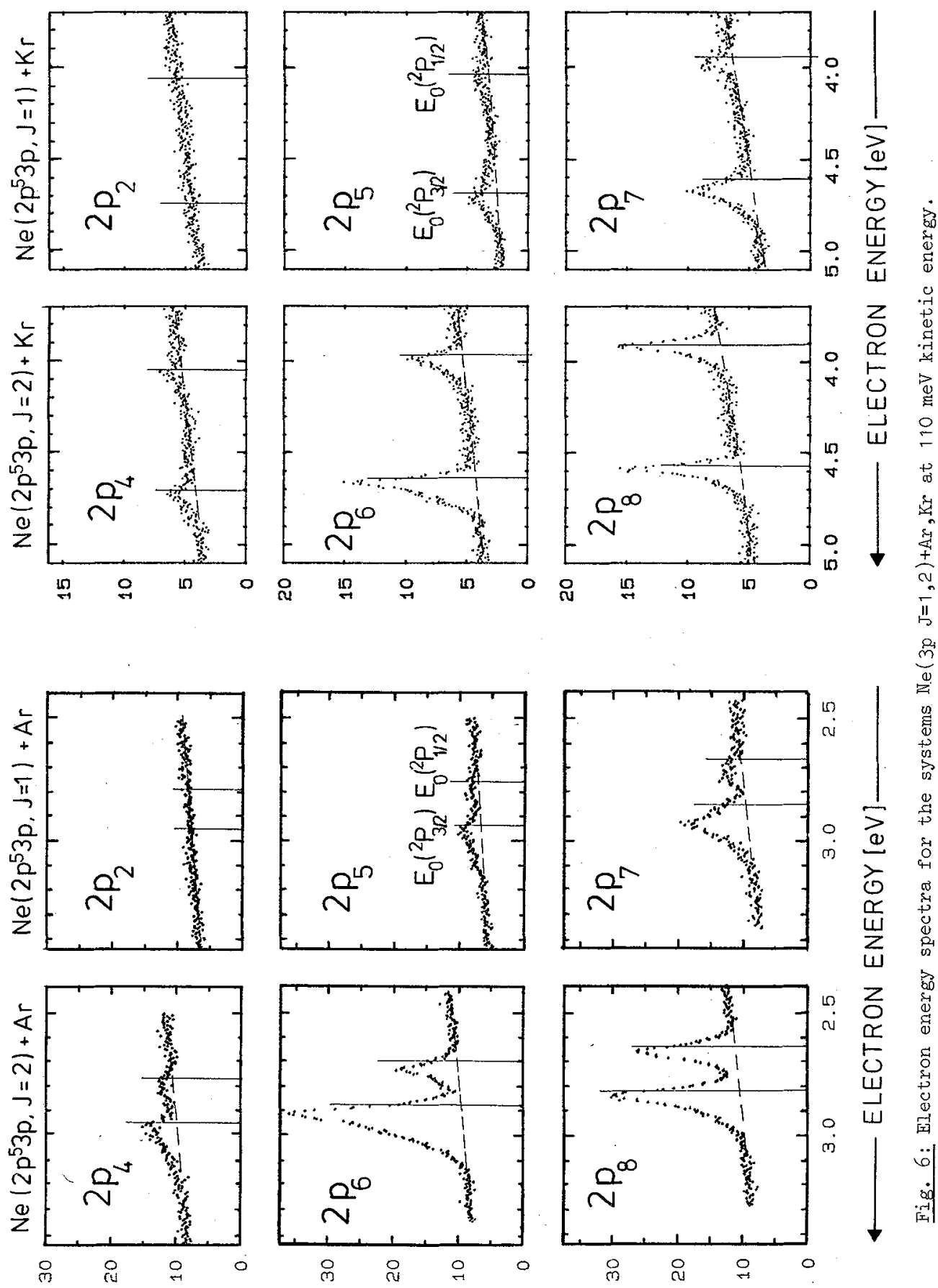

[Jas/SIUNOJ] $\wedge \perp$ ISN 
Table 2: Total Ionization Cross Sections [A2] for $\mathbb{N e}(30 \mathrm{~J}=1,2)+\mathrm{Ar}$

\begin{tabular}{|c|c|c|c|c|c|c|}
\hline \multirow[b]{2}{*}{$\mathrm{Ne}(3 p)$-state } & \multicolumn{2}{|c|}{ EXPERIMENT } & \multicolumn{4}{|c|}{ THEORY ${ }^{\mathrm{a}}$} \\
\hline & $E_{r e l}=58 \mathrm{meV}$ & $110 \mathrm{meV}$ & $E_{r e l}=$ & $58 \mathrm{meV}$ & $110 \mathrm{~m}$ & \\
\hline ive $\left({ }^{3} \mathrm{D}_{2}, 2 \mathrm{p}_{8}\right)$ & $15.3 \pm 0.8$ & $16.4 \pm 1.0$ & 18.3 & & 16.2 & \\
\hline $\mathrm{Ne}\left({ }^{3} \mathrm{D}_{1}, 2 \mathrm{p}_{7}\right)$ & $6.9 \pm 0.9$ & $9.8 \pm 1.0$ & 4.5 & $(7.9)^{b}$ & 9.6 & $(12.2)^{b}$ \\
\hline $\mathrm{Ne}\left({ }^{1} \mathrm{D}_{2}, 2 \mathrm{p}_{6}\right)$ & $11.6 \pm 1.1$ & $13.6 \pm 1.4$ & 15.8 & $(12.9)$ & 15.0 & $(13.6)$ \\
\hline $\operatorname{Ne}\left({ }^{1} p_{1}, 2 p_{5}\right)$ & $1.5 \pm 1.0$ & $4.9 \pm 0.9$ & 3.7 & $(5.5)$ & 3.7 & $(5.2)$ \\
\hline $\mathrm{He}\left({ }^{3} \mathrm{p}_{2}, 2 \mathrm{p}_{4}\right)$ & $3.0 \pm 0.9$ & $5.7 \pm 0.9$ & 5.7 & $(4.5)$ & 5.9 & $(4.8)$ \\
\hline $\mathrm{Ne}\left({ }^{3} \mathrm{p}_{1}, 2 \mathrm{p}_{2}\right)$ & $0.4 \pm 0.4$ & $\begin{aligned} 1.6 & +0.8 \\
- & 1.2\end{aligned}$ & 1.9 & & 2.1 & \\
\hline
\end{tabular}

a Theoretical values obtained with $\Gamma(R)=0.137 \mathrm{eV} \cdot \exp \left(-0.9 \mathrm{R} / \mathrm{a}_{0}\right)$.

$\mathrm{b}$ The values in brackets were calculated with the adiabatic potential curves for the $\Omega=1$ components, see text.

4. Calculation of Potential Energy Curves for Ne(2p $\left.p^{5} l\right)+$ Ar

4.1 Theory

We consider a slow collision between an excited rare gas atom $X$ and a ground state atom $Y$ with the respective configurations

$$
X\left(m p^{5} n\right)+Y\left({ }^{1} S_{0}\right) .
$$

The total energy shall lie in the ionization continuum of $\mathrm{Y}^{+}$. In computing the corresponding potential curves we project out all configurations, which look like $\mathrm{X}\left({ }^{1} \mathrm{~S}_{0}\right)+\mathrm{Y}^{+}+\mathrm{e}^{-}$, where the electron may be in a bound or a continuum state. The very same method was used in the few ab initio calculations that exist for Penningionizing molecular states /e.g.24-26/. The continuum comes in again when computing the autoionization width of the resonance, which is not our purpose.

The symmetry of molecular states $X Y$ is fully described by the wavefunction of $X$, which in turn depends parametrically on the internuclear distance between $X$ and $Y$. The basis states for our treatment are the same as those which are used to treat the isolated $X\left(\mathrm{mp}^{5} \mathrm{nl}\right)$ atom. These states represent two electron (or one-electron-onehole) wavefunctions. They have been discussed extensively by Condon \& Shortley /27/, who define two basis sets which correspond to the LS coupling case and to the $j j$ coupling case, respectively. We denote these basis states by $\mid$ LSJ $\rangle$ and $|K j J\rangle$. $J$ is the total angular momentum of the atom, $L$ the total orbital angular momentum and $S$ the total spin angular momentum. $K$ denotes the total angular momentum of the $\mathrm{mp}^{5}$ hole state and $j$ the same quantity for the nl electron state. All electrostatic interactions in the atoms are diagonal in the ILSJ> basis, whereas spin orbit interaction can be parametrized as a diagonal matrix in the $|\mathrm{KjJ}\rangle$ basis. The necessary transformation between the two basis sets can be done with the aid of a matrix $U$, the elements of which consist essentially of $9 j$-symbols $/ 28 /$. The parameters which are used for describing the electrostatic interactions and the spin orbit interactions are discussed in detail by Condon and Shortley $/ 27 /$.

We define two matrices $A^{E S}$ and $A^{S O}$. $A^{E S}$ contains all electrostatic interactions (expressed by the proper parameters) and is diagonal in the |LSJ> basis. ASO describes the spin orbit interaction with the two conventional parameters $\zeta_{\mathrm{mp}}$ and $\zeta_{\mathrm{nl}}$ and
is diagonal in the $|\mathrm{KJJ}\rangle$ basis. Then we define the matrix A by

$$
A=A^{E S}+U^{\dagger} A^{S O} U \text {. }
$$

Diagonalization of $A$ yields the eigenvalues of the included configurations $X\left(\mathrm{mp}^{5} \mathrm{nl}\right)$, nl variable. The employed parameters are taken from Condon \& Shortley $/ 27 /$. In this 
parametrization, configuration interaction within the atom is not included. Therefore, matrix A blocks into several submatrices $A_{i}$ which correspond to the single configurations $X\left(m^{5} n l\right), X\left(m p^{5} n^{\prime} l^{\prime}\right), \ldots$. This simple method leads to very good results for the rare gas configurations $\mathrm{mp}^{5} \mathrm{~ns}$ and $\mathrm{mp}{ }^{5} \mathrm{nd}$. It was found, however, that $\mathrm{mp}^{5} \mathrm{np}$ configurations cannot be parametrized in this way with the same precision. In this case, the introduction of an effective operator $\alpha \cdot I(L+1)$, which simulates the interaction with other configurations, improves the situation significantly (cf. Feneuille et. al. /29/). At this stage, we resume that it is possible to construct a matrix A according to eq. (4.2), the eigenvalues of which represent the energy levels of the configurations $\mathrm{X}\left(\mathrm{mp}^{5} \mathrm{nl}\right)$ of an excited rare gas atom.

If we wish to obtain information on the molecular states of $\mathrm{X}\left(\mathrm{mp} \mathrm{p}^{5} \mathrm{n}\right)+\mathrm{Y}\left({ }^{1} \mathrm{~S}_{0}\right)$ we must add those interactions which arise when $X$ and $Y$ approach each other. These interactions can be assumed to be of purely electrostatic nature. Thus, they are advantageously described in the IISJ> basis. We conceive now a matrix $B$ which contains the interactions specific for the molecule $X+Y$ in the ILSJ> basis. Diagonalization of the sum of the two matrices $A+B$ will then lead to the eigenvalues and eigenvectors of the molecular states $X+Y$. The molecular interactions include those which couple different configurations $m p^{5} n l$ and $m p^{5} n^{\prime} I^{\prime}$. This causes off-diagonal elements in $B$ which couple different blocks $A_{i}$ and $A_{j}$ within the matrix $A$. At this stage, diagonalization of the sum $A+B$ leads to more accurate results since both spin orbit and (molecular induced) configuration interaction are taken into account.

Now we start to explicitly construct the matrix $B$. We first treat the elements of $B$ which couple states within the same configuration. Let |LSJ> and IL'SJ'> be two states belonging to the same configuration $\mathrm{mp}^{5} \mathrm{nl}$. The coupling operator shall be denoted by $\vec{\nabla}$.. Since $\vec{\nabla}$ is purely electrostatic the spin quantum numbers of both states must be identical. With respect to the nuclear axis, $I, S, J$ shall have the projection quantum numbers $\mathrm{M}_{\mathrm{L}}, \mathrm{M}_{\mathrm{S}}$ and $\mathrm{M}$, resectively. The coupling matrix element can be written as

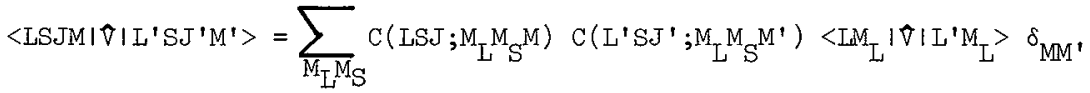

Usually nothing is known about the matrix element $\left\langle L_{L}|\widehat{V}| I^{\prime} M_{L}\right\rangle$. In order to arrive at a practically useful expression we replace the operator $\hat{\nabla}$ by the sum $\nabla_{c}+\nabla_{v}$. $\hat{\nabla}_{\mathrm{v}}$ shall act only on the wavefunction of the valence electron nl. Coupling between the wavefunctions is neglected. Let $l_{c}$ be the resultant orbital angular momentum of the core electrons and $m_{c}$, $m$ the projections of $I_{c}$ and $I$ onto the internuclear axis. Then we express the bracket in eq. (4.3) by

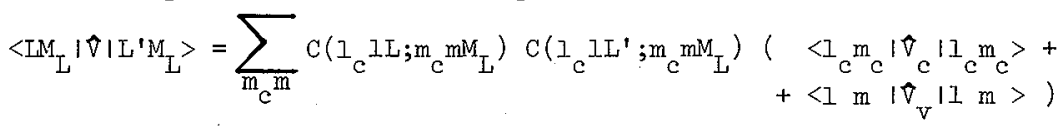

The definition of $\hat{v}_{c}$ and $\hat{v}_{v}$ makes these operators diagonal in $m_{c}$ and $m$, respectively. The wavefunction $\mid \mathrm{Im}>$ can be considered to describe a molecule $\mathrm{X}^{\prime}(\mathrm{nl})+\mathrm{Y}\left({ }^{1} \mathrm{~S}_{0}\right)$. $X^{\prime}$ shall be an atom with a nuclear charge increased by 1 with respect to $X$ but with an additional electron filling the hole in the $m p^{5}$ shell of $X$. The wavefunction $|\mathrm{lm}\rangle$ can be taken as describing $\Sigma$, $\Pi$, ... molecular states of $X^{\prime}(n l)+Y$, depending on the absolute value $\mid \mathrm{ml}$. Interaction with other atomic states $n^{\prime} l^{\prime}$ is neglected so that $\mid \mathrm{Im}>$ is a valence bond type of molecular wavefunction for $X^{\prime}+Y$ (cf. Fano and Fano $/ 30 /$ ). Going from $X^{\prime}+Y$ to $X+Y$ requires (at first order perturbation theory) that the splitting is taken into account which is caused by $\left|\mathrm{m}_{\mathrm{c}}\right|$ taking on different values. Since for $\mathrm{mp}^{5}$. one has $l_{c}=1, \mathrm{~m}_{\mathrm{c}}$ can take the values $-1,0,1$. In order to conserve the center of gravity of terms we require that

$$
\sum_{m_{c}}<l_{c} m_{c}\left|\nabla_{c}\right| I_{c} m_{c}>=0
$$

Thus $\left\langle l_{c} m_{C}\left|\hat{v}_{C}\right| l_{c} m_{C}\right\rangle$ does not describe the potential curves of the molecular ion $\mathrm{X}^{+}(\mathrm{mp})^{5}+\mathrm{Y}\left({ }^{\mathrm{I}} \mathrm{S}_{0}\right)$, but merely the splitting between the $\Sigma$ and II state potentials $V_{\Sigma}$, $\mathrm{V}_{\pi}$. We can identify 


$$
\begin{aligned}
& \left\langle I_{c} m_{C}=0\left|v_{c}\right| l_{c} m_{c}=0\right\rangle=-(2 / 3) \cdot\left(v_{I I}-v_{\Sigma}\right) \\
& \left\langle I_{c} m_{C}= \pm 1\left|v_{c}\right| I_{c} m_{C}= \pm 1\right\rangle=+(1 / 3) \cdot\left(v_{I I}-v_{\Sigma}\right)
\end{aligned}
$$

Thus we have found a form for the coupling matrix element in eq. (4.3) which allows to make use of available, sometimes even experimental information: $\left\langle\operatorname{lm}\left|\hat{v}_{\mathrm{v}}\right| \mathrm{Im}\right\rangle \mathrm{shall}$ be taken as a potential curve for atom $Y$ and the alkali atom next to $X$ in the periodic system. It must be kept in mind, however, that it is the valence bond potential curve and not the exact one which is required as input data for $\left\langle\operatorname{lm}\left|\hat{v}_{\mathrm{v}}\right| \mathrm{Im}\right\rangle$.

Now we consider those elements of matrix B which couple different configurations $m p^{5} n l$ and $m p^{5} n^{\prime} l^{\prime}$. We define an operator $\widehat{w}$ which describes the electrostatic interaction between the one-electron states $|n I\rangle$ and $\left|n^{\prime} I^{\prime}\right\rangle$ which is caused by the approach of the atom $Y$. W is diagonal in the projection quantum number $m$, $i . e$. the matrix element $\left\langle n I m|\nabla| n^{\prime} I{ }^{\prime} m^{\prime}\right\rangle$ vanishes unless $m=m^{\prime}$. The matrix element of $B$ can be

$$
\begin{aligned}
& \begin{array}{l}
\text { written as } \\
\text { where }
\end{array}
\end{aligned}
$$

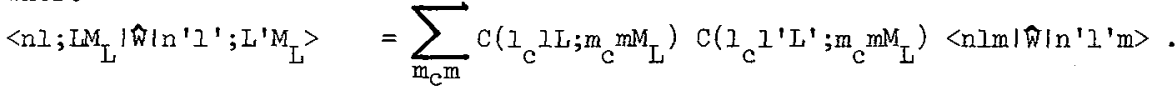

\subsection{Computation of the Potential Curves for $\mathrm{Ne}\left(2 p^{5} 3 \mathrm{~s}, 3 p\right)+\mathrm{Ar}$}

We apply the formulae from the preceeding section to the computation of the molecular states of $\mathrm{Ne}^{*}+\mathrm{Ar}$ which dissociate to $\mathrm{Ar}$ and $\mathrm{Ne}\left(2 \mathrm{p}^{5} 3 \mathrm{~s}, 3 \mathrm{p}\right)$. We incorporate the configurations $2 p^{5}$ ss and $2 p^{5} 3 p$ in the treatment.

The first step consists in constructing the matrix A according to eq. (4.2). AlI necessary information can be found in /27,29/. The parameters used are listed in Table 3. The terms obtained by diagonalization of A deviate only very little from the experimental values /31/. For the configuration $2 p^{5} 3 s$ the difference never exceeds $0.06 \mathrm{meV}$, for the configuration $2 \mathrm{p}^{5} 3 \mathrm{p}$ the deviation is always below $0.9 \mathrm{meV}$. It follows that the accurate asymptotic limits are guaranteed for the potential curves we are about to calculate. The remaining task is now to find the proper input

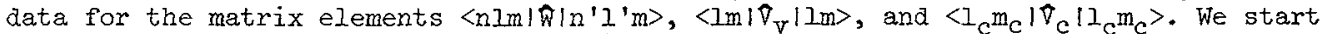
with the latter, as defined in eq. (4.6). We need the splitting between the $\Sigma$ and the II potential for $\mathrm{ArNe}^{+}\left(2 \mathrm{p}^{5}\right)$ as a function of internuclear distance. Hausamann and Morgner /32/ compute this quantity with a semiempirical method and find that it is well represented by an exponential in the relevant $\mathrm{R}-\mathrm{range}\left(4-7 \mathrm{a}_{0}\right)$. In the present calculation we have used $\mathrm{V}_{\pi}-\mathrm{V}_{\Sigma}=230 \mathrm{eV} \cdot \exp \left(-1.73 \mathrm{R} / \mathrm{a}_{\mathrm{O}}\right)$.

Table 3: Numerical Values for the $\mathrm{Ne}\left(2 \mathrm{p}^{5} 3 \mathrm{~s}, 3 \mathrm{p}\right)$ Atoric Parameters

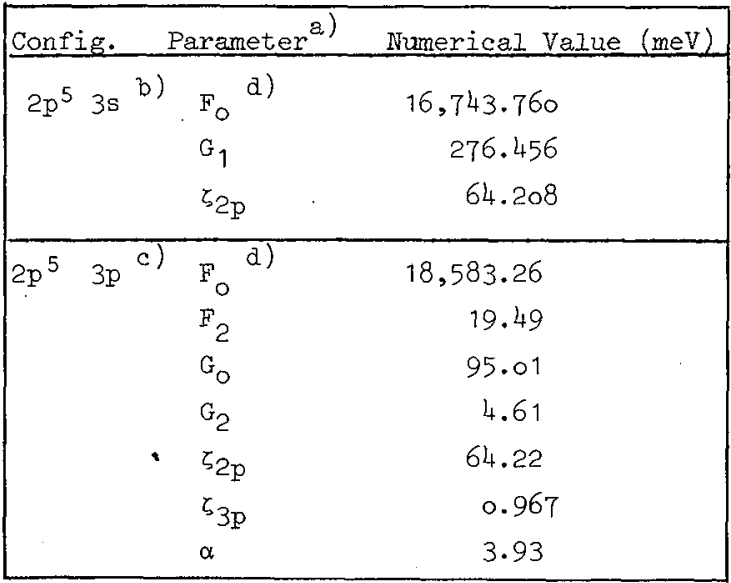

a) Definitions as in ref. /27/

b) Fit of parameters: this work

c) Parameters taken from ref. /29/

d) The values of $F_{0}$ have been adjusted to reproduce the term values of $\mathrm{Ne}^{*}$ relative to the $\mathrm{Ne}$ ground state 


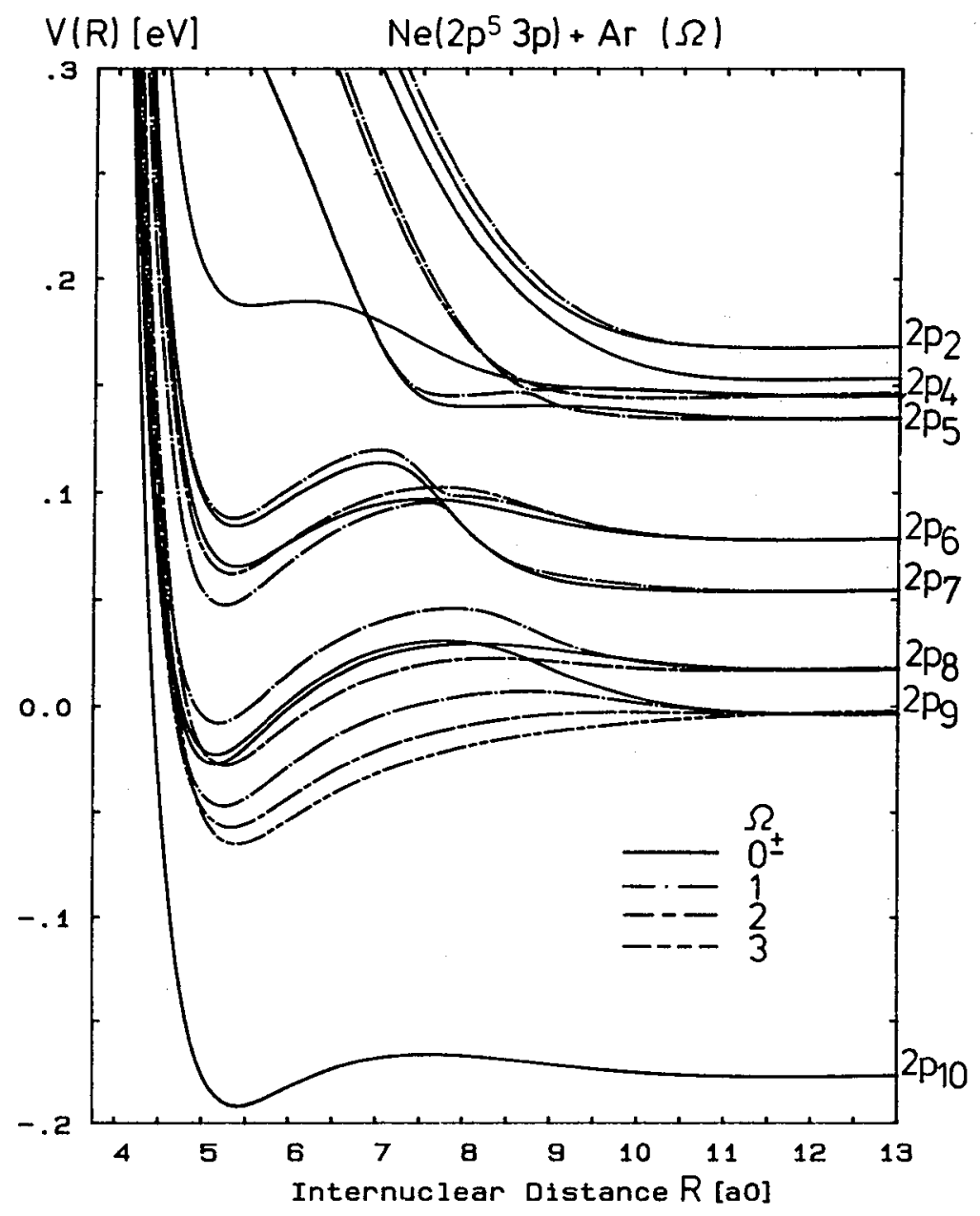

Fig. 7: Calculated adiabatic potentials for $\mathrm{Ne}\left(2 \mathrm{p}^{5} 3 \mathrm{p}\right)+\mathrm{Ar}$.

The zero point of the energy scale is set to $\mathrm{E}\left(2 \mathrm{p}_{9}\right)=18.555 \mathrm{eV}$. 
Now we try to find reasonable input data for the matrix elements $\left\langle n I m|\hat{W}| n^{\prime} I{ }^{\prime} m\right\rangle$ (eq. 4.8) and $\left\langle\operatorname{lm}\left|\hat{V}_{\mathrm{V}}\right| \mathrm{Im}\right\rangle$ (eq. 4.4). Here we use results of Düren et al /33/ for $\mathrm{Na}(\mathrm{nl})+$ Ar; they applied a pseudopotential method and fitted the parameters of the pseudopotential to expeximental scattering data /33,34/. Their quantities $v_{11}^{\mu},(R)$. (as defined, e.g., in /33-35/) are related to our matrix elements through:

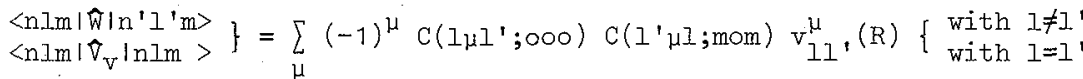

Fig. 7 shows the calculated Ne(3p)+Ar potential energy curves. In the relevant Rrange 5-8a, the curves with dominant $3 p \pi-c h a r a c t e r$ are attractive, whereas those with dominant $3 p \sigma-c h a r a c t e r$ are repulsive. In some cases, nice avoided crossings show up, e.g. between the $\Omega=1$ potentials for $2 p_{6}$ and $2 p_{7}$. The character of the different calculated potential curves provides an immediate qualitative understanding of the experimentally-found state dependence of the cross sections: for collision energies in the range $50-100 \mathrm{meV}$, the potential curves for the $2 \mathrm{p}_{1} 0^{-2 \mathrm{p}_{6}}$ states allow the penetration to rather small distances $\left(R \simeq 5 a_{0}\right)$, where the autoionization rate is very large; in contrast, the potential curves for the $2 p_{5}$, $2 p_{4}$ states, and especially for the $2 \mathrm{p}_{3}-2 \mathrm{p}_{1}$ states, prevent closer distances to be reached than about $7 a_{0}$, resulting in smaller cross sections than for the $2 p_{10}-2 p_{6}$ states.

\section{Discussion}

5. 1 Comparison of Experimental and Theoretical Total Ionization Cross Sections for $\mathrm{Ne}(3 \mathrm{p})+\mathrm{Ar}$

Using the adiabatic potential energy curves obtained in section 4, we have carried out classical calculations of the total ionization cross sections (for the formulae, see e.g. /36/), making the following assumptions:

1) each $\Omega$-state is weighted with a statistical factor $\mathrm{S}_{\Omega}$ according to:

$$
\sigma_{\text {tot }}=\sum_{\Omega=0}^{J} \mathrm{~s}_{\Omega} \sigma_{\Omega}
$$

with $S_{\Omega}=1 /(2 J+1)$ for $\Omega=0$ and $S_{\Omega}=2 /(2 J+1)$ for $\Omega \geq 1$. J is the total angular momentum of the $\mathrm{Ne}(3 \mathrm{p} J)$-state in question.

2) Transitions between $\Omega$-states (rotational coupling) and between neighbouring Ne( $3 p$ )-states (radial and/or rotational coupling) are ignored. In view of the sharp avoided crossings between the $\Omega=1$ states for $2 p_{7} / 2 p_{6}$ and $2 p_{5} / 2 p_{4}$, it is more adequate to use the corresponding diabatic potential curves in calculations of the respective cross sections. A Landau-Zener analyis $/ 37 /$ showed that the crossing probability is above $80 \%$ even at the low energies of $50-100 \mathrm{meV}$. In Table 2, we have also listed (in brackets) the cross sections obtained if the adiabatic $\Omega=1$ curves are used in the calculation.

3) A single exponential function $\Gamma(R)$ (3.2) is assumed to represent the autoionization width for all the multiplet states, independent of $\Omega$. This simple choice with an optimized exponent $\gamma$ produces surprisingly good agreement with experiment for the total unpolarized cross sections; it does not suffice, however, to understand the polarization effects (see below).

For comparison with the experimental data, the appropriate kinetic energy average of the cross sections was_carried out. The average collision energy for the beam-gas data $\left(\bar{v}_{\mathrm{Ne}}=800 \mathrm{~m} / \mathrm{s}\right)$ is $\overline{\mathrm{E}}_{\mathrm{rel}}=58 \mathrm{meV}$, the one for the beam-beam data $(\overline{\mathrm{v}}=1200 \mathrm{~m} / \mathrm{s})$ is $\overrightarrow{\mathrm{E}}_{\mathrm{rel}}=110 \mathrm{meV}$. We have varied the critical parameter $\gamma$ in eq. (3.2) in the range $0.6^{1} a_{0}{ }^{-1} \leqq \gamma \leqq 1.2 a_{0}{ }^{-1}$ with simultaneous adjustment of $c$ to scale the absolute size of the cross sections. The best overall agreement was obtained for $\gamma=0.9 a_{0}{ }^{-1}$, with $\mathrm{C}=0.137 \mathrm{eV}$ (Table 2), but the whole range (0.8-1.0) $\mathrm{a}_{0}^{-1}$ can be considered to produce satisfactory results. It is interesting to note that this choice for $\gamma$ appears to be also adequate for reproducing the energy dependence of the metastable $\mathrm{Ne}\left(3 \mathrm{~s}{ }^{3} \mathrm{P}_{2,0}\right)+\mathrm{Ar}$ total ionization cross section $/ 38,39 /$ in the range $10 \mathrm{meV} \leqq \mathrm{E}_{\mathrm{rel}} \leqq 200 \mathrm{meV}$. We note, however, that the various experimental metastable cross sections do not agree very well, as discussed in $/ 40 /$. 


\subsection{Polarization dependence of $\mathrm{Ne}\left(3 \mathrm{p}{ }^{3} \mathrm{D}_{3}\right)+\mathrm{Ar}$ cross sections}

In order to observe a dependence of the cross section on the asymptotically varied population of the magnetic substates, there has to be a $\Omega$-selectivity in the collision system. This may be due to strong differences in the potential energy curves or can also be due to a strong dependence of the autoionization width $\Gamma$ on $\Omega$.

The first question, which has to be answered, is: what is the actual $\Omega$-population in the relevant range of distances, where autoionization occurs $\left(5-8 a_{0}\right)$, for different asymptotic polarizations? If one ignores coupling to neighbouring multiplet states, the simplest model is that of "free evolution" for all impact parameters. This model would be adequate in the absence of any energy-splitting between the different $\Omega$-states, which, of course, is not the case. The next step of sophistication is the "critical radius" model /e.g. 4, 10/. The system evolves freely until a critical distance $R_{c}$, at which the sudden transition from the lab frame to the close coupled body-fixed frame occurs. The system $\mathrm{Na}(3 p)+\mathrm{Hg} / 4 /$ and especially $\mathrm{Na}(3 \mathrm{p})+\mathrm{Na}{ }^{+}$ $/ 10 /$ appear to be good examples for this case. Ne $\left(3 \mathrm{p}^{3} \mathrm{D}_{3}\right)+\mathrm{Ar}$, however, is more complicated. Close coupling calculations have been carried out /42/ to follow the evolution of the asymptotic $\Omega$-population on straight-line trajectories down to $\bar{R}=6 a_{O}$ (the "average" distance of autoionization) in order to learn more about the relevant $\Omega$-population of the autoionizing quasi-molecule as a function of impact parameter $b$; (for $\mathrm{b}>6 \mathrm{a}_{\mathrm{O}}, \overline{\mathrm{R}}=\mathrm{b}$ was used). Couplings to the neighbouring $2 \mathrm{p}_{8}-$ state were included, but found to be not very important (transfer to $2 p_{8}$ below $10 \%$ ). When those quasimolecular $\Omega$-populations were built into the calculation of the total ionization cross sections, a polarization ratio $Q=1.03$ was obtained at $\overline{\mathrm{E}}_{\mathrm{rel}}=110 \mathrm{meV}$ under the assumption of an $\Omega$-independent $\Gamma(R)$, using $C=0.137 \mathrm{eV}, \gamma=0.9 \mathrm{a}_{\mathrm{o}} \mathrm{I}$ (see above). The experimental polarization effect $(Q=1.57)$ is much larger, and we are forced to introduce an $\Omega$-dependence of $\Gamma(R)$. This is not unexpected: one envisages (Fig.8) that autoionization will occur most likely if the Ne-core hole has o-orientation and is filled by transfer from a o-electron in Ar. Morgner /41/ has discussed Penning ionization in terms of reduced amplitudes $u_{m}+m_{c}$, where $m_{c}$ is the projection of the Necore orbital angular momentum, and $m+$ is the projection of the final-state Ar ${ }^{+}$hole onto the internuclear axis. The previous statement then can be expressed by saying that $u_{\infty}$ dominates. If one ignores all the other amplitudes, the $\Omega=3$ entrance channel does not contribute to ionization, and this assumption leads to a polarization ratio of $Q=1.55$, i.e. gives the correct trend. One can show, however, that the experimentally-observed polarization dependence of the $\mathrm{Ar}^{+}\left({ }^{2} \mathrm{P}_{3 / 2}\right) / \mathrm{Ar}^{+}\left({ }^{2} \mathrm{P}_{1 / 2}\right)$ intensity ratio requires contributions from (at least) $u_{11}$ at the $10 \%$ level.
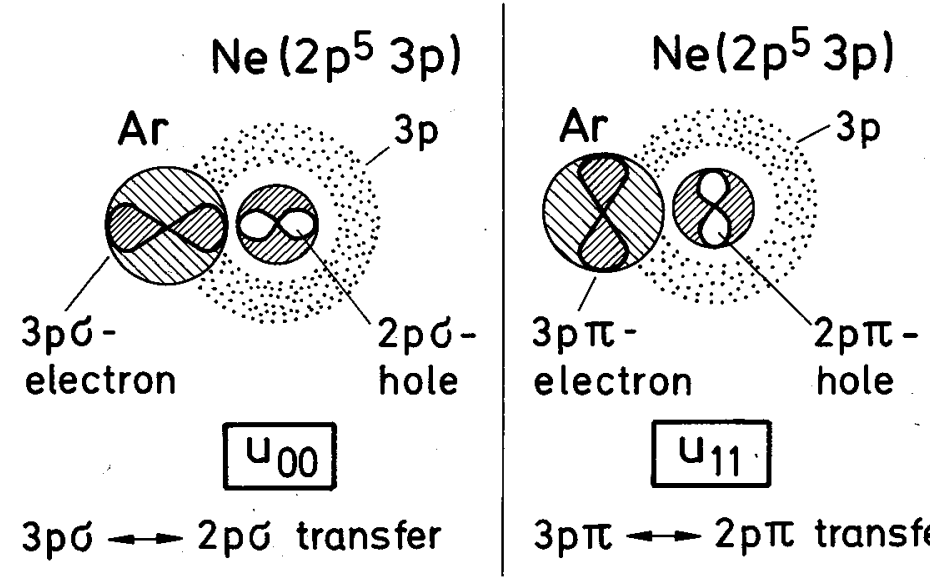

\section{$3 p \pi \longrightarrow 2 p \pi$ transfer}

Fig. 8: Illustration of two of the reduced autoionization amplitudes $u_{m_{+}} m_{c}$;
the dominant amplitude is $u_{o o}$. 
Finally, we briefly discuss the polarization dependence of the shape of the electron spectrum for $\mathrm{Ne}\left(3 \mathrm{p}{ }^{3} \mathrm{D}_{3}\right)+\mathrm{Ar}$ (Fig. 5) in the light of the calculated potential curves (Fig. 7). We have constructed semiempirical potential curves for $\mathrm{Ne}+\mathrm{Ar}^{+}$from available information $/ 13,43-45 /$ and expected analogies with $\mathrm{He}+\mathrm{Ar} \mathrm{r}^{+}$, as will be discussed elsewhere. We restrict the discussion to the $\operatorname{Ar}^{+}\left({ }^{2} \mathrm{P}_{1} / 2\right)$ electron peak, which corresponds to the single ionic channel $\mathrm{V}^{+}\left({ }^{2} \Pi_{1 / 2}\right)$. The corresponding curve has a well depth of $50 \mathrm{meV}$ at $\mathrm{R}_{\mathrm{e}}^{+} \simeq 5.1 \mathrm{a}_{0}$. The relevant difference potentials $\mathrm{V}_{\Omega}^{*}(R)$ $\mathrm{V}^{+}\left({ }^{2} \pi_{1 / 2}\right)$ exhibit relative minima and maxima, which lead to singularities in classical calculations of cross sections. Quantum mecharical calculations of the separate $\Omega$-spectra yield peaks with electron energy shifts $\Delta(\Omega)=E^{\mathrm{P}}$ el $(\Omega)-\mathrm{E}_{\mathrm{O}}$ (relative to the ${ }^{2} \mathrm{P}_{1} / 2$ nominal energy) of about $\Delta(0)=+40 \mathrm{meV}, \Delta(1)=+10 \mathrm{meV}, \Delta(2)=-4 \mathrm{meV}$ and $\Delta(3)=-14 \mathrm{meV}$. The experimental peak occurs at $\Delta \simeq+18 \mathrm{meV}$ with a shoulder around $\Delta \simeq+45 \mathrm{meV}$. The shoulder can be without doubt associated with ionization due to $\Omega=0$. The dominant contribution to the experimental peak appears to be due to $\Omega=1$ with minor admixtures from $\Omega=2$ (and possibly $\Omega=3$ ). The rise of both the $\Omega=0$ and $\Omega=1$ fraction when changing from $\pi_{\perp}$ to $\pi_{\|}$is compatible qualitatively with calculated effective $\Omega$-populations. In order to explain the relative intensities of the different s-contributions, as distinguishable from the observed peak shape, one needs a propensity in the autoionization in favour of $\Omega=0,1$, which is again compatible with the dominance of the amplitude $u_{0 O}$. A more detailed discussion of the polarization effects will be given elsewhere.

6. Conclusions

Ionizing collisions of laser-excited $\mathrm{Ne}(3 \mathrm{p})$ atoms with $\mathrm{Ar}$ and $\mathrm{Kr}$ have been studied by electron and ion spectrometry. The measured strong state-dependence of the total ionization cross section has been recovered in a calculation based on theoretical potential curves and a single autoionization width common to all channels. The observed behaviour mainly reflects the amount of admixture of the attractive $3 \mathrm{p} \pi-$ and repulsive 3po-orbitals, resulting in large differences of the respective (average) distance of closest approach. Significant polarization effects have been observed in the total and partial ion cross sections as well as in the shapes and finestructure populations of the electron spectra, especially for $\mathrm{Ne}\left(3 \mathrm{p}{ }^{3} \mathrm{D}_{3}\right)+\mathrm{Ar}$. The polarization effects can only be understood with more refined models, requiring $\Omega$-dependent autoionization probabilities such that the dominant (but not the only) amplitude is due to $\sigma \rightarrow \sigma$ electron transfer.

This work has been supported by the Deutsche Forschungsgemeinschaft (SFB 91). We thank R.J. Allan for his collaboration, D. Hausamann for useful correspondence, and $R$. Düren for providing the numerical data of their a.lkali-rare gas potentials.

\section{$\underline{\text { References }}$}

/1/: HERTEL I.V., and STOLL W., Adv. At. Mol. 13 (1978) 113 REILAND W., JAMIESON G., TITTES U., HERTEL I.v., Z. Phys. A307 (1982) 51

/2/ DÜREN R., GRÖGER W., HASSELBRINK E., LIEDTKE R., J. Chem. Phys. 74 (1981) 6806

13/ SILVER J.A., BLAIS N.C., KWEI G.H., J. Chem. Phys. I1 (1979) 3412

/4/ HÜWEL L., MAIER J., PAULY H., J. Chem. Phys. 76 (1982) 4961

/5/ PESNELLE. A., et al., J. Phys. B14 (1981) 1827; B16 (1983) L193

/6/ WEINER J., and POLAK-DINGELS P., J. Chem. Phys. 74 (1981) 508

/7/ MESTDA.H J.M., BERLANDE J., DE PUJO P., CUVELLIER J., BINET A., Z. Physik $\mathrm{A} 304_{4}$ (1982) 3

18/ RETTNER C.T., anḋ ZARE R.N., J. Chem. Phys. 77 (1982) 2416

19/ KIRCZ J.G., MORGZNSTERN R., NIENHUIS G., Phys. Rev. Lett. 48 (1982) 610 
/10/ SCHMIDT H., BÄHRIMG A., MEYER E., MILLER B., Phys. Rev. Lett. 48 (1982) 1008

/11/ HOTOP H., LORENZEN J., ZASTROW A., J. Electron Spectrosc. Rel. Phen. 23 (1981) 347

/12/ LORENZEN J., MORGNER H., BUSSERT W., RUF M.-W., HOTOP H., Z. Physik A310 (1983) 141

/13/ HOTOP H., in:"Electronic and Atomic Collisions", North Holland, 1980, p. 271

/14/ BUSSERT W., et al., Abstracts of Papers, XII ICPEAC, Gatiinburg, 1981, p. 522

/15/ BUSSERT W., GANZ J., HOTOP H., RUF M.-W., SIEGEL A., WAIBEL H., BOTSCHWINA P., LORENZEN J., Chem. Phys. Lett. 95 (1983) 277

/16/ SIEGEL A., GANZ J., BUSSERT W., HOTOP H., J. Phys. B16 (1983) 2945

/17/ GANZ J., STEGEI A., BUSSERT W., HARTH K., RUF M.-W., HOTOP H., GEIGER J., FINK M., J. Phys. B16 (1983) L569

/18/ BUSSERT W., et al., Abstracts of Papers, XIIICEPAC, Berlin 1983,p. 619

/19/ RUF M.-W., BREGEL T., HOTOP H., J. Phys. B16 (1983) 1549

/20/ WEISSManin G., GANZ J., SIEGEL A., WAIBEI H., HOTOP H., Opt. Commun. 49 (1984) 335

/21/ PRISANT M.G., RETTNER C.T., ZARE R.N., J. Chem. Phys. 75 (1981) 2222

/22/ HARTMETZ P., and SCHMORANZER H., Phys. Lett. 93A (1983) 405

/23/ NIENHUIS G., Phys. Rev. A26 (1982) 3137

/24/ MILLER W.H., SLOCOMB C.A., SCHAEFER III H.F., J. Chem. Phys. 56 (1972) 1347

/25/ HICKMAN A.P., ISAACSON A.D., MILLER W.H., J. Chem. Phys. 66 (1977) 1483

/26/ BENTLEY J., J. Chem. Phys. 33 (1980) 1805

/27/ CONDON E.U., and SHORTLEY G.H., The Theory of Atomic Spectra, Cambridge University Press, 1963

128/ EDMONDS A.R., Drehimpulse in der Quantenmechanik, BI 53/53a, 1964

/29/ FENEUILLE S., KLAPISCH M., KOENIG E., LIBERMAN S., Physica 48 (1970) 571

/30/ FANO U., and FANO Physics of Atoms and Molecules, An Introduction to the Structure of Matter, Chicago University Press, 1972

/31/ MOORE CH.E., Atomic Energy Levels, 1971, NSRDS-NBS 35

/32/ HAUSAMANN D., and MORGNER H., private communication (results to be published)

/33/ DÜREN R., HASSELBRINK E., MORITZ G., Z. Physik A307 (1982) 1

134/ DÚREN R., Adv. At. Mol. Phys. 16 (1980) 55

/35/ BAYLIS W.E., J. Chem. Phys. 51. (1969) 2665

/36/ MILLER W.H., J. Chem. Phys. 52 (1970) 3563

/37/ ZENER C., Proc. Roy. Soc. (London) A137 (1932) 696

/38/ TAivg S.Y., MaRCUS A.B., MuschiITZ Jr. E.E., J. Chem. Phys. 56 (1972) 566

/39/ NeYNaber R.H., and Magnuson G.D., Phys. Rev. A11. (1975) 865

/40/ GREGOR R.W., and SISKA P.E., J. Chem. Phys. 74 (1981) 1078

/41/MORGNER H., Comm. At. Mol. Phys. 11 (1982) 271

$142 /$ ALLAN R.J., and BUSSERT W., unpublished material

/43/ PRATT S.T., and DEHMER P.I., J. Chem. Phys. 76 (1982) 3433

/4h/ / DABROWSKI I., and HERZBERG G., J. Mol. Spectrose. 89 (1981) 491

/45/ HOFFMARV V., and MORGNeR H., J. Phys. B12 (1979) 2857 